\title{
O impacto do trabalho The Forms of Capital de Pierre Bourdieu na literatura científica internacional
}

\author{
Maurício de Vargas Corrêa
}

mauricio.be@hotmail.com

Gonzalo Rubén Alvarez

gonzalorubenalvarez@gmail.com

Samile Andrea de Souza Vanz samilevanz@terra.com.br

Sônia Elisa Caregnato sonia.caregnato@ufrgs.br

Universidade Federal do Rio Grande do Sul, Faculdade de Biblioteconomia e Comunicação, Porto Alegre, RS, Brasil

DOI: https://doi.org/10.26512/rici.v12.n1.2019.19527

Recebido/Recibido/Received: 2017-12-18

Aceitado/Aceptado/Accepted: 2018-08-03

Resumo: Aborda o impacto do trabalho The Forms of Capital de Pierre Bourdieu na literatura científica internacional por meio da análise das citações feitas a ele em publicações científicas. Através de um estudo bibliométrico, 5.631 documentos indexados na base Web of Science, que citaram o trabalho desde sua publicação até 2016, foram analisados e caracterizados quanto ao ano de publicação, idioma, tipologia documental, periódico de publicação, áreas do conhecimento, temas, instituições e países citantes. Os resultados sugerem (1) o crescimento exponencial do volume de citações recebidas, (2) o inglês como o idioma predominante nas publicações citantes, (3) a expressividade das citações de artigos científicos e artigos de revisão, (4) a grande dispersão dos artigos citantes em 1.637 títulos de periódicos, (5) a Sociologia, a Educação e Pesquisa Educacional e a Administração como as áreas que mais citaram o trabalho do autor, (6) a formação de clusters de termos teoricamente relacionados e a existência de linhas de investigação dentro do corpus, (7) a variedade de instituições citantes e (8) a concentração de publicações citantes nos países da América do Norte, Europa e Oceania. Conclui que o impacto do trabalho The Forms of Capital pode ser observado na produção científica de diversos países e áreas do conhecimento.

Palavras-chave: Pierre Bourdieu. análise de citações.

The impact of Pierre Bourdieu's The Forms of Capital in international scientific literature Abstract: It addresses the impact of Pierre Bourdieu's work The Forms of Capital in the international scientific literature by analyzing its citations in scientific publications. Through a bibliometric study, 5,631 documents indexed in the Web of Science database that cited the work since its publication until 2016, were analyzed and characterized according to the year of publication, language, documentary typology, publication periodical, areas of knowledge, institutions and countries. The results suggest (1) the exponential growth of the volume of citations received, (2) English as predominant language in 
citation publications, (3) the expressivity of scientific papers and articles citations, (4) citation articles in 1,637 titles of periodicals, (5) Sociology, Education and Educational Research and Management as the areas that most cited the work of the author, (6) the formation of clusters of theoretically related terms and the existence of investigation lines inside the corpus (7) the variety of citing institutions and (8) the concentration of citation publications in the countries of North America, Europe and Oceania. It concludes that the impact of The Forms of Capital work could be observed in the scientific output of several countries and areas of knowledge.

Keywords: Pierre Bourdieu. citation analysis.

El impacto del trabajo The Forms of Capital de Pierre Bourdieu en la literatura científica internacional Resumen: Aborda el impacto de la obra de Pierre Bourdieu The Forms of Capital en la literatura científica internacional mediante el análisis de sus citas en publicaciones científicas. A través de un estudio bibliométrico, se analizaron y caracterizaron 5,631 documentos indexados en la base de datos Web of Science que citaron el trabajo desde su publicación hasta 2016, según el año de publicación, idioma, tipología documental, publicación periódica, áreas de conocimiento, instituciones y países. Los resultados sugieren (1) el crecimiento exponencial del volumen de citas recibidas, (2) el inglés como idioma predominante en las publicaciones de citas, (3) la expresividad de los artículos científicos y las citas de artículos, (4) artículos de citas en 1,637 títulos de publicaciones periódicas, (5) Sociología, Educación e Investigación y Gestión Educativa como las áreas que más citaron el trabajo del autor, (6) la formación de agrupaciones de términos teóricamente relacionados y la existencia de líneas de investigación dentro del corpus (7) la variedad de citas instituciones y (8) la concentración de publicaciones de citas en los países de América del Norte, Europa y Oceanía. Concluye que el impacto del trabajo de The Forms of Capital podría observarse en la producción científica de varios países y áreas de conocimiento.

Palabras-clave: analise de citas. Pierre Bourdieu.

\section{Introdução}

Pierre Bourdieu pode ser considerado um dos sociólogos mais citados e influentes no Brasil (BORTOLUCl; JACKSON; PINHEIRO FILHO, 2015). Sua obra produziu conceitos inovadores que foram apropriados por diferentes áreas do saber. Ao longo de sua trajetória, o sociólogo francês buscou conciliar teoria e prática, desenvolvendo conceitos, mas com a preocupação constante de testá-los em campo. A consistência e o poder explicativo de suas contribuições teóricas são tão proeminentes que seus conceitos permanecem relevantes e atuais apesar do tempo decorrido desde as suas formulações. De acordo com Minayo (2017), Bourdieu tornouse um dos cientistas sociais mais lidos no mundo pelo mérito dos temas que abordou, pela força dos conceitos que construiu e pelo aporte epistemológico e metodológico que eles representam até hoje.

Em um de seus trabalhos, The Forms of Capital, Bourdieu apresenta e discute os conceitos de capital econômico, capital cultural e capital social. Essas noções são usadas para compreender as posições dos agentes sociais em determinados campos que conformam a estrutura social. Enquanto algumas formas de capital são herdadas, outras podem ser 
adquiridas pelo esforço de seu possuidor. O poder, status ou prestígio (capital simbólico) está diretamente relacionado com a quantidade e a qualidade do capital acumulado por um determinado sujeito. As formas de capital terão maior ou menor legitimidade de acordo com os campos nos quais os sujeitos estejam inseridos. Dessa forma, o capital pode ser visto como um elemento que perpassa os diferentes contextos sociais.

Considerando-se a relevância do legado de Pierre Bourdieu para as diferentes áreas do conhecimento e a inexistência de um estudo acerca da influência de um de seus importantes escritos sobre o conceito de capital, o presente artigo pretende analisar, de maneira sistemática, o impacto do capítulo The Forms of Capital na literatura por meio das citações feitas à obra em publicações científicas internacionais. A análise de citações é uma metodologia que contribui com a identificação de trabalhos importantes e da influência que eles exercem na comunidade científica, além de possibilitar o mapeamento das relações entre autores e áreas do conhecimento (GARFIELD, 1979). A visibilidade de determinados autores, obras, teorias e metodologias é evidenciada pela análise de citações, o que a torna um dos principais métodos da bibliometria (VANZ; CAREGNATO, 2003).

A análise de citações é normalmente realizada através dos índices de citação disponíveis nas bases de dados Web of Science e Scopus. Tendo em vista as características da obra The Forms of Capital - um capítulo publicado originalmente em alemão em uma área pouco abrangida pelas bases de dados - o estudo reconhece suas limitações no que tange à cobertura incipiente de capítulos nas bases de dados e seu impacto no volume de citações atribuídas a obras das Ciências Sociais e Humanidades, que tem no livro seu documento principal para comunicação científica. Outra importante limitação para o estudo é a baixa representatividade da literatura científica de língua não inglesa em bases de dados. A escolha de bases de dados que arrolam a produção científica internacional pode, desse modo, produzir um viés maior para idiomas e países cuja literatura esteja indexada nessas bases de dados. Não obstante, considera-se que este é um estudo exploratório que pode revelar a difusão do trabalho do autor ao longo dos anos e em variadas áreas do conhecimento.

Utilizando a análise de citações, este trabalho tem como objetivo apresentar um panorama do impacto da obra The Forms of Capital na literatura científica internacional e retratar o alcance deste trabalho de Pierre Bourdieu desde a sua publicação até o presente. As seções a seguir apresentam aspectos da vida e obra de Pierre Bourdieu, a metodologia utilizada na pesquisa, os resultados encontrados e as considerações finais. 


\section{Pierre Bourdieu: vida e obra}

Pierre Félix Bourdieu nasceu no dia 1ํ de agosto de 1930 em Béarn, uma região rural do sudoeste da França, e faleceu em 23 de janeiro de 2002, na cidade de Paris, aos 71 anos. Cursou o ensino fundamental em uma escola camponesa e o ensino médio no Liceu da cidade de Pau. Por ter se destacado, recebeu uma bolsa de estudos e foi aconselhado a ingressar em uma escola de elite que reunia os melhores estudantes do país: a École Normale Supérieure (SILVA; HAYASHI, 2012). Graduou-se em Filosofia, em 1954, na mesma instituição que acolheu cientistas e pensadores ilustres como Louis Pasteur, Émile Durkheim, Jean-Paul Sartre e Michel Foucault (ÉCOLE NORMALE SUPÉRIEURE, [2007?]):

Treinado para juntar-se à alta casta dos filósofos, a espécie intelectual suprema na França do pós-Segunda Guerra, ele abraçou, ao contrário, a Sociologia, uma disciplina então inferior e moribunda, ajudando a revitalizála e a renová-la, e cuja influência na esfera pública ele propagou como ninguém. (WACQUANT, 2002, p. 96).

Em 1955, Pierre Bourdieu é chamado à Versalhes pela bandeira francesa, mas em virtude de sua rebeldia em relação à autoridade militar, é enviado à Argélia para servir na missão de "pacificação" da colônia do norte da África. A vivência da dolorosa realidade das guerras travadas pela França contra o nacionalismo argelino despertou em Bourdieu o interesse pela sociedade argelina sob o ponto de vista político e científico e foi um aspecto crucial para a sua transição da Filosofia para as Ciências Sociais. Em seu primeiro livro, Sociologie de l'Algérie, publicado em 1957, o autor faz um alerta sobre as contradições da sociedade colonizada e sobre as desilusões do movimento nacionalista. A obra, considerada um estudo acadêmico impecável, sintetiza o conhecimento histórico, etnológico e sociológico sobre a Argélia (WACQUANT, 2002).

Durante sua trajetória, Bourdieu publicou mais de 300 trabalhos, abordando temas relacionados à educação, cultura, literatura, arte, mídia, linguística e política, sob a perspectiva sociológica e antropológica (SILVA; HAYASHI, 2012). Segundo Catani (2002), entre seus livros de maior impacto estão La distinction: critique sociale du jugement (1979), Homo academicus (1984), La noblesse d'État: grandes écoles et esprit de corps (1989), As regras da arte: gênese e estrutura do campo literário (1992), Réponses: por une anthropologie réflexive (com Loïc J. D. Wacquant, 1992), A miséria do mundo (1993), Meditações pascalianas (1997), além de outros livros de grande apelo junto ao grande público, como Sobre a televisão (1996), Contrafogos: táticas para enfrentar a invasão neoliberal (1998) e Contrafogos 2: por um movimento social europeu (2001).

Sua obra gira em torno de conceitos formulados para compreender a sociedade, como habitus, campo, capital e violência simbólica (SILVA; HAYASHI, 2012). Para Valle (2013), a 
originalidade do pensamento de Pierre Bourdieu está principalmente no fato de desconstruir oposições conceituais, remover as fronteiras disciplinares em prol do trabalho sociológico e estender o olhar da Sociologia para além da dimensão econômica, o que lhe possibilitou mostrar e reconhecer a estreita ligação entre essa e as demais dimensões sociais. De fato, os dados apresentados a seguir demonstram que as proposições teóricas de Bourdieu avançaram para além das ciências sociais, rompendo barreiras disciplinares e geográficas.

Um dos conceitos-chave da sociologia de Pierre Bourdieu é a noção de capital cultural. O conceito foi formulado pelo autor nos anos 1960 e se tornou uma das mais poderosas categorias analíticas da teoria social e da pesquisa educacional contemporâneas (NOGUEIRA, 2017). O capital cultural surge, a partir de seus estudos sobre a escola, para explicar as desigualdades no desempenho escolar de estudantes de diferentes origens sociais, que não poderiam ser compreendidas somente pela perspectiva econômica. Segundo Bourdieu (1986), o conceito consegue romper com as ideias provenientes do senso comum e das teorias do capital humano que veem o sucesso ou o fracasso acadêmico como um efeito de aptidões naturais.

O trabalho The Forms of Capital consiste em um capítulo de livro, publicado pela primeira vez em 1983 no idioma alemão, e traduzido para o inglês em 1986, no qual Pierre Bourdieu apresenta as três formas que o capital pode assumir. O capital econômico é aquele que pode ser convertido imediatamente em dinheiro e institucionalizado na forma de direitos de propriedade. O capital cultural é institucionalizado sob a forma de qualificações educacionais e pode ser convertido em capital econômico em determinadas circunstâncias. Por fim, o capital social é constituído por obrigações sociais, podendo ser convertido em capital econômico sob determinadas condições e institucionalizado na forma de títulos de nobreza (BOURDIEU, 1986). A posse das diferentes formas de capital contribui para a legitimação e manutenção do poder que indivíduos ou grupos exercem sobre outros nos diversos contextos sociais.

\section{Procedimentos metodológicos}

Para analisar o impacto do trabalho The Forms of Capital, foi realizado um estudo bibliométrico, de caráter exploratório, usando como fonte de dados a base Web of Science (WoS). Apesar de todas as limitações da escolha desta base de dados para análise de citações de um capítulo proveniente da área de Ciências Sociais (ARCHAMBAULT; LARIVIÈRE, 2010), considerou-se a opção pertinente para atender os objetivos de um estudo exploratório. Neste momento, avaliou-se que a coleta de citações em livros não seria possível devido ao tempo 
necessário para o procedimento, e o uso de bases de dados específicas não permitiria a recuperação das citações.

A escolha da WoS recai sobre o fato de a base ser amplamente utilizada para estudos de citação, além de permitir a classificação das publicações indexadas em categorias de assunto (WCs) e, consequentemente, a visualização das áreas do conhecimento nas quais o trabalho de Bourdieu (1986) foi utilizado. Dessa forma, a especificidade das 252 categorias de assunto da WoS foi o principal critério para a escolha da base. Vale destacar que os artigos citantes recebem a classificação por assunto de acordo com o periódico no qual foram publicados.

O corpus do estudo foi constituído por 5.631 publicações científicas indexadas na WoS que citaram o capítulo The Forms of Capital. Para recuperar os registros na base, foi realizada uma pesquisa de referência citada usando como expressão de busca o sobrenome do autor e o título do trabalho em todos os idiomas para os quais ele foi traduzido, quais sejam: inglês, alemão, espanhol e italiano. Para ampliar os resultados, as buscas pelo capítulo em inglês foram realizadas sem o artigo the, pois se observou que, em alguns casos, a referência ao trabalho de Bourdieu (1986) era registrada sem o artigo. Embora o trabalho também tenha sido traduzido para o italiano, não foram recuperadas citações ao documento. Cabe destacar que The Forms of Capital ainda não possui tradução para os idiomas francês e português.

Ao todo, foram realizadas cinco buscas através do recurso pesquisa de referência citada da WoS. Em todas as buscas, o sobrenome do autor foi inserido no campo autor citado. Para garantir a precisão dos resultados, foi utilizada a combinação do sobrenome do autor com o título da obra através do operador booleano AND. Os campos título citado e publicação citada foram empregados alternadamente nas buscas pelas diferentes versões do título da obra a fim de ampliar a revocação da base. Nas buscas por título citado, foram recuperados documentos em inglês, alemão e espanhol. Já por publicação citada, a base retornou registros em inglês e alemão.

As buscas foram realizadas nos três índices principais da WoS: Science Citation Index Expanded (SCI-EXPANDED), Social Sciences Citation Index (SSCI) e Arts \& Humanities Citation Index (A\&HCI). O recorte temporal estabelecido foi de 1983 a 2016 e a coleta de dados foi realizada em 12 de julho de 2017. Os dados foram exportados em pacotes de arquivos contendo os registros completos. Com o auxílio do software BibExcel, esses arquivos foram unificados e convertidos para outros formatos, a fim de viabilizar as análises realizadas com os softwares BibExcel, Pajek, VosViewer e Philcarto. Os resultados foram organizados em gráficos, tabelas e grafos, de modo a permitir uma melhor visualização. 


\section{Resultados e discussão}

Conforme pode ser observado no Gráfico 1, a primeira citação ao trabalho The Forms of Capital foi feita no ano de 1985, apenas dois anos após a publicação do original em alemão. Nos anos seguintes, o volume de citações foi aumentando progressivamente, ajustando-se muito bem a uma curva de crescimento exponencial $\left(R^{2}\right.$ 0,9897). Observa-se que as citações, conforme o gráfico 1, que perfaziam algumas dezenas nas décadas 1980 e 1990, passaram a centenas nos anos 2000, totalizando 5.631 citações desde o lançamento da obra até 2016. Conforme Archambault e Larivière (2010), os documentos em Ciências Sociais demoram para começar a serem citados, e tem seu pico cerca de dez anos após a publicação. Os resultados encontrados parecem indicar que o interesse pela obra do autor tem aumentado ao longo do tempo e que as contribuições teóricas e conceituais presentes em The Forms of Capital permanecem relevantes para os pesquisadores, mesmo decorrido o pico de citação previsto pela literatura para a área de Ciências Sociais.

Gráfico 1 - Distribuição das citações ao trabalho The Forms of Capital por ano

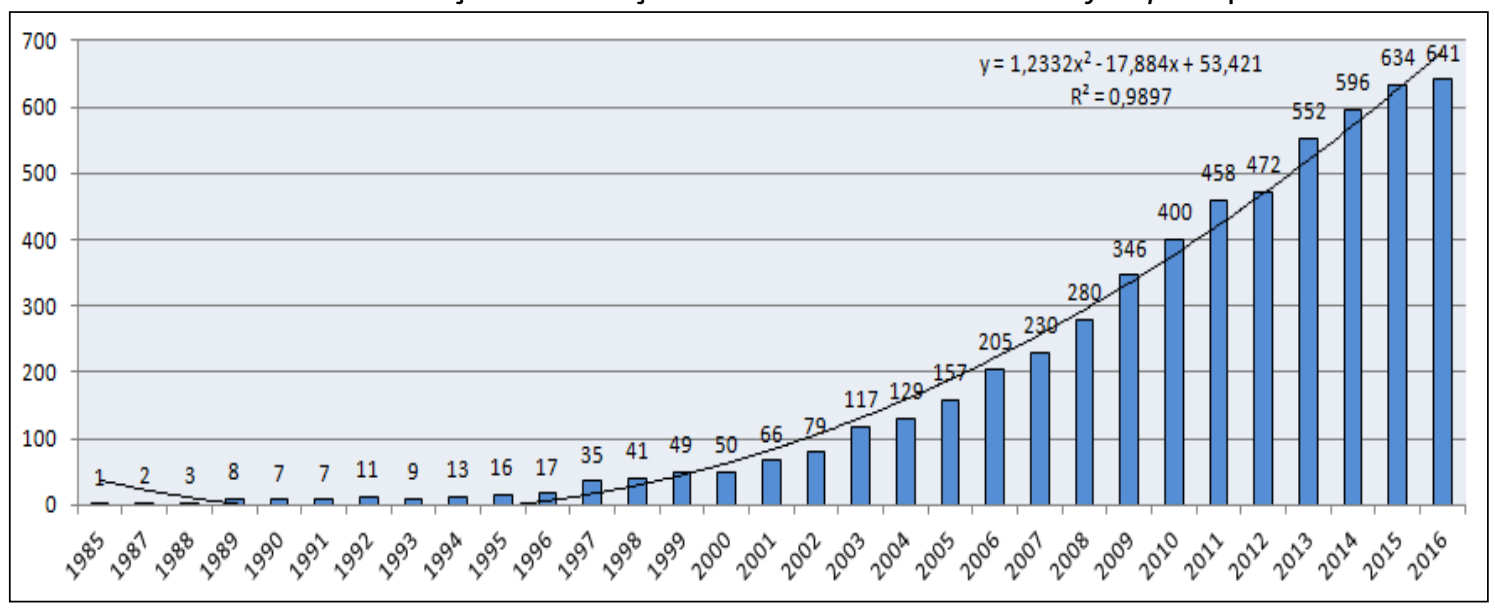

Fonte: Dados da pesquisa.

Outro aspecto analisado diz respeito ao idioma dos artigos citantes. Como pode ser visualizado na Tabela 1, 93,16\% dos artigos que citaram o trabalho de Bourdieu (1986) foram publicados em inglês. $\mathrm{O}$ idioma francês está presente em apenas vinte e dois artigos do corpus $(0,39 \%)$. Inicialmente, a baixa quantidade de artigos citantes na língua nativa do autor parece intrigante. No entanto, sabe-se que as bases de dados têm seu foco na literatura científica internacional publicada predominantemente em inglês (ARCHAMBAULT; LARIVIÈRE, 2010). Dessa forma, o viés da base pode ter exercido influência sobre os resultados. Por outro lado, a quase totalidade de artigos citantes em inglês e, especialmente, o aparecimento de uma grande diversidade de idiomas, demonstram a repercussão que a obra de Pierre Bourdieu tem entre a comunidade científica de vários idiomas. 
Tabela 1 - Distribuição das citações ao trabalho The Forms of Capital por idioma

\begin{tabular}{lll}
\hline Idiomas & \multicolumn{1}{c}{ Publicações } & $\%$ \\
\hline Inglês & 5.246 & 93,16 \\
\hline Alemão & 231 & 4,10 \\
\hline Espanhol & 48 & 0,85 \\
\hline Francês & 22 & 0,39 \\
\hline Checo & 16 & 0,28 \\
\hline Português & 12 & 0,21 \\
\hline Russo & 12 & 0,21 \\
\hline Croata & 11 & 0,20 \\
\hline Eslovaco & 7 & 0,12 \\
\hline Sueco & 6 & 0,11 \\
\hline Norueguês & 4 & 0,07 \\
\hline Italiano & 4 & 0,07 \\
\hline Africâner & 2 & 0,04 \\
\hline Holandês & 2 & 0,04 \\
\hline Japonês & 2 & 0,04 \\
\hline Polonês & 2 & 0,04 \\
\hline Turco & 1 & 0,02 \\
\hline Catalão & 1 & 0,02 \\
\hline Lituano & 1 & 0,02 \\
\hline Húngaro & 1 & 0,02 \\
\hline Total & $\mathbf{5 . 6 3 1}$ & $\mathbf{1 0 0 , 0 0}$ \\
\hline \multicolumn{1}{|l}{ Fonte: } & &
\end{tabular}

Fonte: Dados da pesquisa.

Em relação aos tipos documentais das publicações que citaram o trabalho The Forms of Capital, a análise revelou uma predominância de artigos científicos e artigos de revisão, com, respectivamente, $90,24 \%$ e 4,44\%. Também foram identificados trabalhos apresentados em evento, material editorial, revisões de livros, capítulos de livros, cartas, entre outros. Os periódicos onde foram publicados os artigos que citaram Bourdieu (1986) também foram objeto de análise. Ao todo foram identificados 1.637 títulos, indicando grande dispersão e ampla variedade de áreas que fazem uso desse trabalho.

Um fato interessante é que a revista Actes de la Recherche en Sciences Sociales, fundada por Pierre Bourdieu em 1975, aparece na 276a posição entre os periódicos que publicaram trabalhos citantes. De acordo com Wacquant (2002), a publicação surgiu como um "grupo de trabalho sociológico" permanente, formado para derrubar as barreiras do 
formalismo acadêmico, das disciplinas e do pensamento social pré-construídos, bem como desenvolver um verdadeiro internacionalismo científico capaz de restabelecer a unidade de uma ciência social autocrítica. Embora o propósito inicial da publicação seja ambicioso, a análise das citações revelou que o periódico não consta entre os títulos que mais publicaram os trabalhos citantes. Uma explicação para o fato seria o idioma da publicação - francês - que de certa forma poderia limitar o alcance internacional das publicações.

Segundo Silva e Hayashi (2012), a produção intelectual de Pierre Bourdieu disseminouse para além da Sociologia e foi incorporada por outras áreas do conhecimento. No presente estudo, a análise de citações identificou 154 domínios nos quais o trabalho de Bourdieu (1986) foi mencionado. Observa-se que a área de origem do autor - Sociologia - ainda reúne o maior volume de citações, correspondendo a 1.266 artigos citantes (22,5\%). Em seguida despontam as áreas da Educação e Pesquisa Educacional com 987 artigos (17,5\%) e a Administração com 417 artigos (7,4\%). As demais áreas do conhecimento possuem uma representatividade menor no corpus. No entanto, chama a atenção, a grande variedade de áreas. A figura 1 apresenta uma rede formada pelas relações entre as principais áreas dos artigos citantes.

Figura 1 - Rede de WCs com mais de 32 citações ao trabalho The Forms of Capital

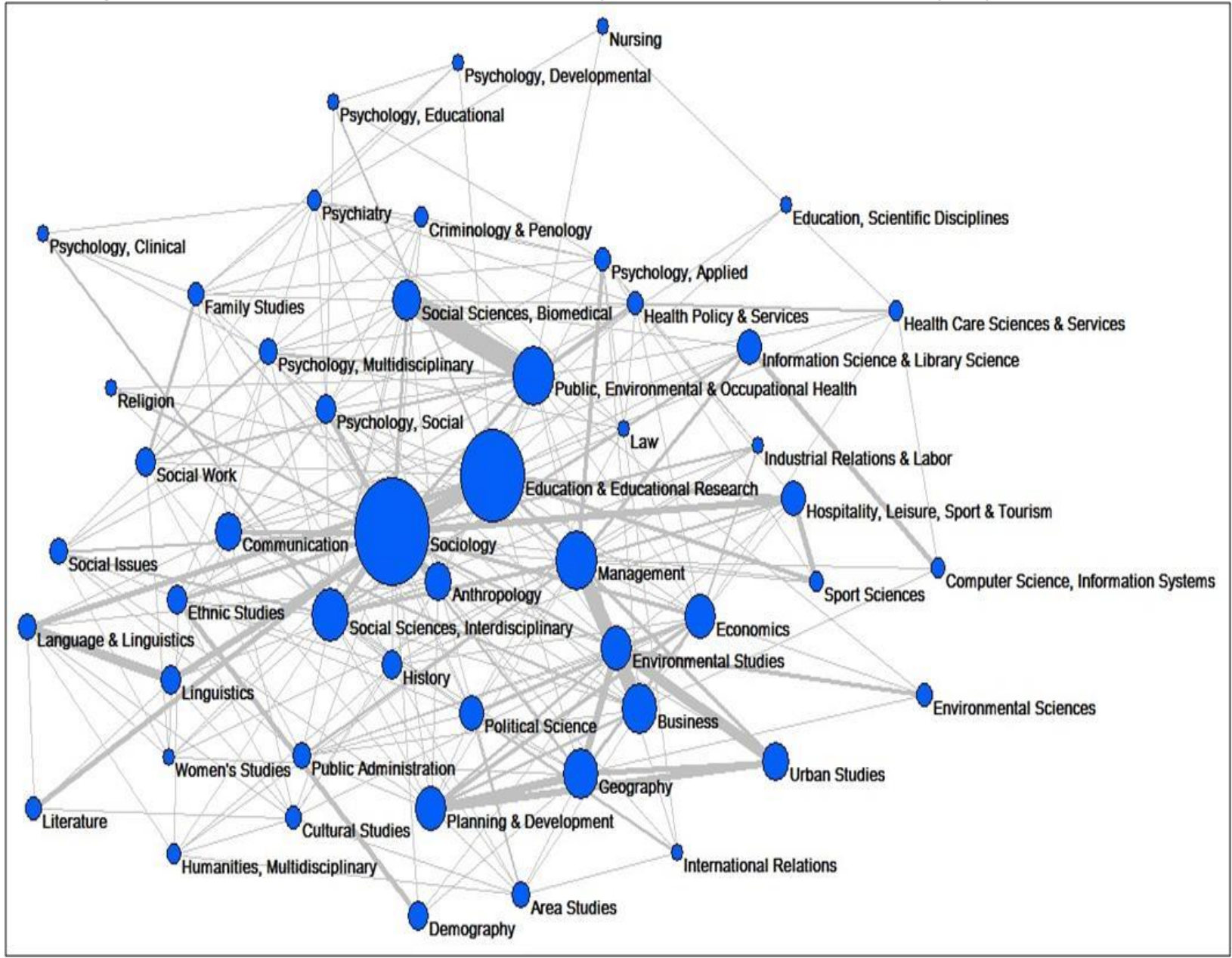


Fonte: Dados da pesquisa.

Como os resultados sugerem, um dos domínios mais influenciados pelo pensamento de Pierre Bourdieu é a Educação. Os estudos de Pierre Bourdieu sobre a escola inspiraram a formulação de seus principais conceitos (habitus, campo, capital cultural, social, simbólico, violência simbólica, distinção), se multiplicaram e diversificaram, incluindo a ação, a autoridade e o trabalho pedagógico (VALLE, 2013). O estudo dos mecanismos de reprodução das desigualdades sociais, usando o sistema escolar como um dos exemplos mais importantes, permitiu o surgimento de conceitos que se tornaram muito caros à Sociologia e a outras áreas do conhecimento que se valem das contribuições de Pierre Bourdieu.

Catani, Catani e Pereira (2001) desenvolveram um estudo sobre a apropriação da obra de Pierre Bourdieu no campo da Pesquisa Educacional com base na análise de 288 artigos publicados por autores brasileiros em 20 periódicos especializados em Educação no período de 1971 a 2000. No trabalho, os autores identificaram três categorias básicas de apropriação: a apropriação incidental, que consiste em referências rápidas ao trabalho do autor; a apropriação conceitual tópica, na qual os conceitos do autor são mobilizados para reforçar argumentos ou resultados obtidos dentro de um quadro terminológico que não necessariamente é o do autor; e a apropriação do modo de trabalho, onde os utensílios teóricos propostos por Bourdieu são acionados em realidades empíricas precisas e uma diversidade maior de obras é referenciada.

Embora as considerações apresentadas por Catani, Catani e Pereira (2001) não possam ser diretamente comparadas com os resultados do presente estudo, em função dos recortes estabelecidos e das abordagens metodológicas utilizadas, pode-se constatar que as contribuições teóricas e conceituais de Pierre Bourdieu vêm sendo apropriadas por pesquisadores da área de Educação e Pesquisa Educacional tanto em âmbito nacional, como demonstra o estudo dos autores, como em âmbito internacional, como sugerem os resultados desta pesquisa.

O trabalho de Bourdieu (1986) também tem sido bastante citado no campo da Administração. Sieweke (2014) desenvolveu um estudo das citações à obra de Pierre Bourdieu em artigos publicados até o ano de 2012 em nove periódicos da América do Norte e Europa, a fim de identificar as contribuições do trabalho de Pierre Bourdieu na área dos Estudos Organizacionais (Management and Organizational Studies ou MOS). Os resultados do estudo sugerem um crescimento na proporção de artigos citantes no período de 1980 a 2012, aliado a uma alta frequência de citações por pesquisadores europeus; os conceitos de capital, habitus e campo como os mais citados nos trabalhos analisados; e o aumento na profundidade das 
discussões em relação ao trabalho de Bourdieu ao longo do tempo. Desse modo, pode-se perceber que os resultados do trabalho de Sieweke (2014) são semelhantes aos deste estudo em termos de crescimento no número de citações a Pierre Bourdieu durante o período analisado e na importância do conceito de capital e, mais precisamente, do capital social, dentro do corpus de análise.

Uma análise geral dos resultados revela que o trabalho The Forms of Capital também foi utilizado por diferentes especialidades da área da saúde, como a psicologia; a psiquiatria; a enfermagem, a gerontologia; a medicina geral e interna; a nutrição e a odontologia, para citar alguns exemplos. Os resultados são interessantes, pois o sociólogo não publicou estudos específicos sobre a saúde e a prática médica. No entanto, orientou trabalhos no Centro de Sociologia Europeia centrados nas práticas de saúde. Além disso, a revista Actes de la Recherche en Sciences Sociales, dirigida por Bourdieu no período 1975 a 2002, constituiu um espaço de publicação de trabalhos relacionados à saúde e à doença. No período de 1975 a 2001, dois números da revista foram dedicados à temática do corpo, onde a apresentação e os primeiros artigos são da autoria de Bourdieu, demonstrando sua preocupação com o assunto. Os artigos publicados na revista mostram-se multifacetados e apresentam interfaces entre diferentes disciplinas (MONTAGNER, 2006).

Também é possível observar citações a The Forms of Capital nas áreas das ciências ambientais, ciência da computação, música, teatro, biologia, engenharia civil, genética e nanotecnologia. A diversidade de áreas dos artigos citantes demonstra que as contribuições de Pierre Bourdieu vão além do seu campo de origem, como apontaram Silva a Hayashi (2012) em seu trabalho sobre a influência de Pierre Bourdieu na área da Bibliometria. Conforme foi mencionado anteriormente, ao longo de sua trajetória acadêmica o autor trabalhou com temas de diferentes áreas do conhecimento sob o enfoque sociológico. Isso explica de certo modo por que sua influência pode ser percebida em áreas do conhecimento tão distintas.

Um dos objetivos do estudo foi identificar os temas dos artigos citantes. A partir de uma análise dos termos que aparecem nas palavras-chave dos autores e nas keywords plus ${ }^{1}$, foi possível constatar que determinados temas tendem a aparecer relacionados nos artigos que compõem o corpus formando clusters, isto é, conjuntos de nós densamente agrupados. $\mathrm{Na}$ figura 2, os nós (círculos) representam os termos, enquanto as arestas correspondem às ligações entre eles. Pode-se observar que foram formados cinco clusters nas cores azul, verde,

\footnotetext{
${ }^{1}$ As keywords plus são palavras-chave atribuídas aos artigos de forma automática pela Web of Science (WoS) com base nos títulos dos trabalhos citados. A vantagem das keywords plus sobre as palavraschave fornecidas pelos autores é que as primeiras indexam assuntos que não foram indicados e podem melhorar a recuperação dos documentos na base.
} 
vermelho, amarelo e lilás e que os três primeiros clusters apresentam maior número de nós. No cluster azul, o termo "capital social" aparece em destaque.

Figura 2 - Rede de termos extraídos das palavras-chave e keywords plus dos documentos que citam o trabalho The Forms of Capital

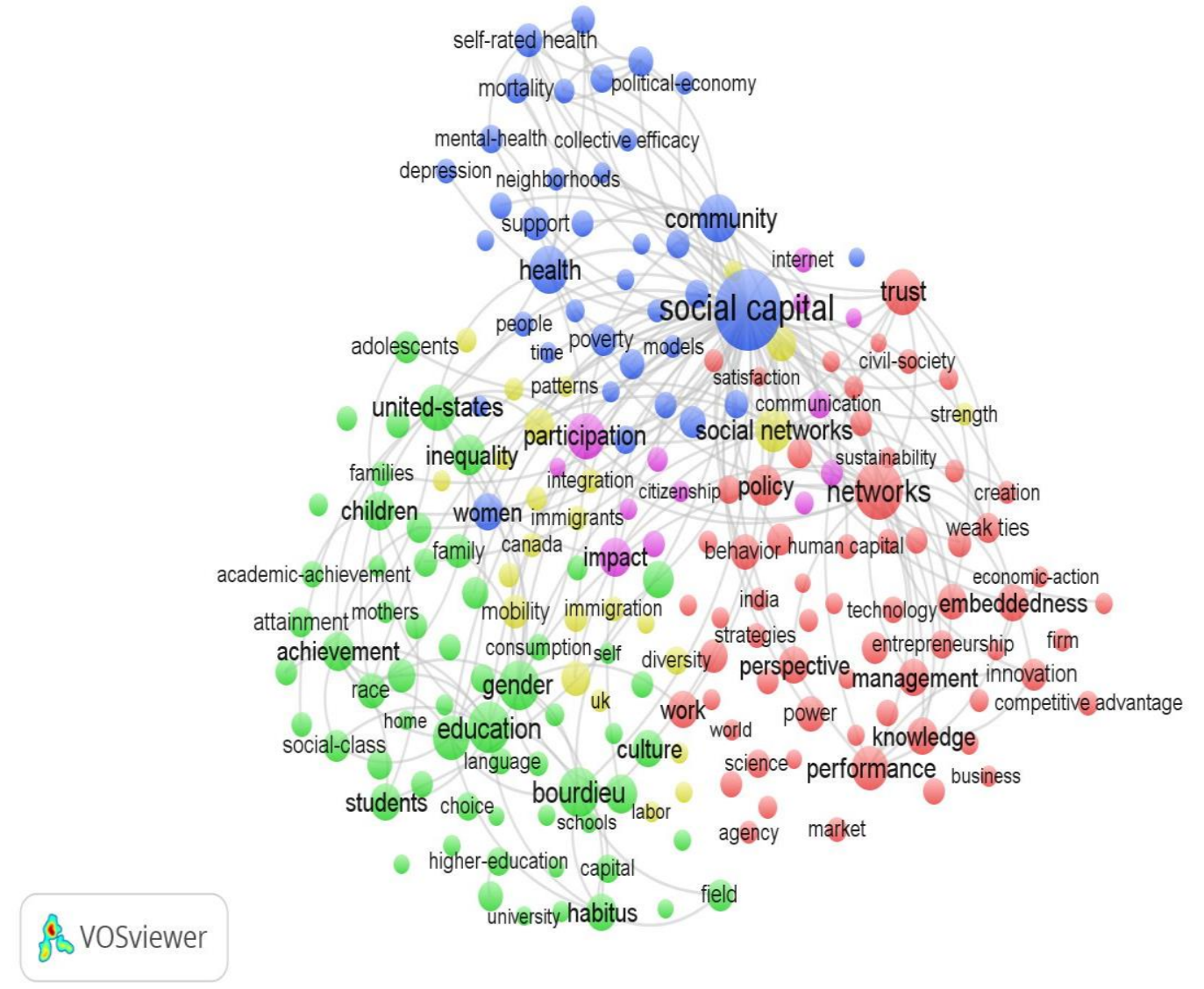

Fonte: Dados da pesquisa.

Uma análise detalhada dos clusters revela que os termos que aparecem conectados por arestas também estão conceitualmente relacionados com a obra de Pierre Bourdieu. É o caso, por exemplo, dos termos educação, classe social, estudantes, criança, família, cultura, habitus e desigualdade, que aparecem no cluster verde. De acordo com Ferreira (2013), a noção de herança familiar, principalmente cultural, aparece associada com a questão do desempenho escolar na concepção do autor. Bourdieu também estabelece uma relação entre o papel da escola e a reprodução e legitimação das desigualdades sociais. Dessa forma, os clusters formados pelos termos extraídos das palavras-chave dos autores e keywords plus estão de acordo com as formulações teóricas propostas por Pierre Bourdieu em sua obra. 
A análise da origem institucional das publicações que compõem o corpus indica que os autores citantes são provenientes de 8.623 instituições, corroborando a ideia de grande difusão do trabalho The Forms of Capital. Na Tabela 2, é possível visualizar as dez instituições que mais citaram a obra, localizadas na Austrália, Canadá, Estados Unidos e Reino Unido, todas consideradas instituições de grande prestígio.

Tabela 2 - Instituições de filiação dos autores que citam o trabalho The Forms of Capital

\begin{tabular}{lccl}
\hline \multicolumn{1}{c}{ Instituição } & Publicações & \% & \multicolumn{1}{c}{ País } \\
\hline University of London & 59 & 0,68 & Reino Unido \\
Harvard University & 59 & 0,68 & EUA \\
University of Wisconsin & 55 & 0,64 & EUA \\
University of Toronto & 55 & 0,64 & Canadá \\
University of Manchester & 50 & 0,58 & Reino Unido \\
University of Queensland & 49 & 0,57 & Austrália \\
University of British Columbia & 47 & 0,55 & Canadá \\
King's College London & 47 & 0,55 & Reino Unido \\
University of Illinois & 45 & 0,52 & EUA \\
University of North Carolina & 42 & 0,49 & EUA \\
\hline
\end{tabular}

Fonte: Dados da pesquisa.

Por fim, o Mapa 1 apresenta a distribuição dos trabalhos citantes por país ou região geográfica. Pode-se observar que o alcance do trabalho The Forms of Capital se estende por todas as regiões do globo. No entanto, a maior concentração de trabalhos citantes está nos Estados Unidos (26,65\%), Reino Unido (18,05\%), Austrália (7,02\%), Alemanha (6,45\%) e Canadá $(5,74 \%)$, o que coincide com os dados da Tabela 2. Por outro lado, a ocorrência de citações ao trabalho de Bourdieu (1986), no continente africano, é baixa, e está concentrada em apenas alguns países. Na América Latina, também é possível observar uma baixa incidência de citações a esse trabalho do autor. Novamente, este resultado pode estar relacionado com a cobertura da WoS. 


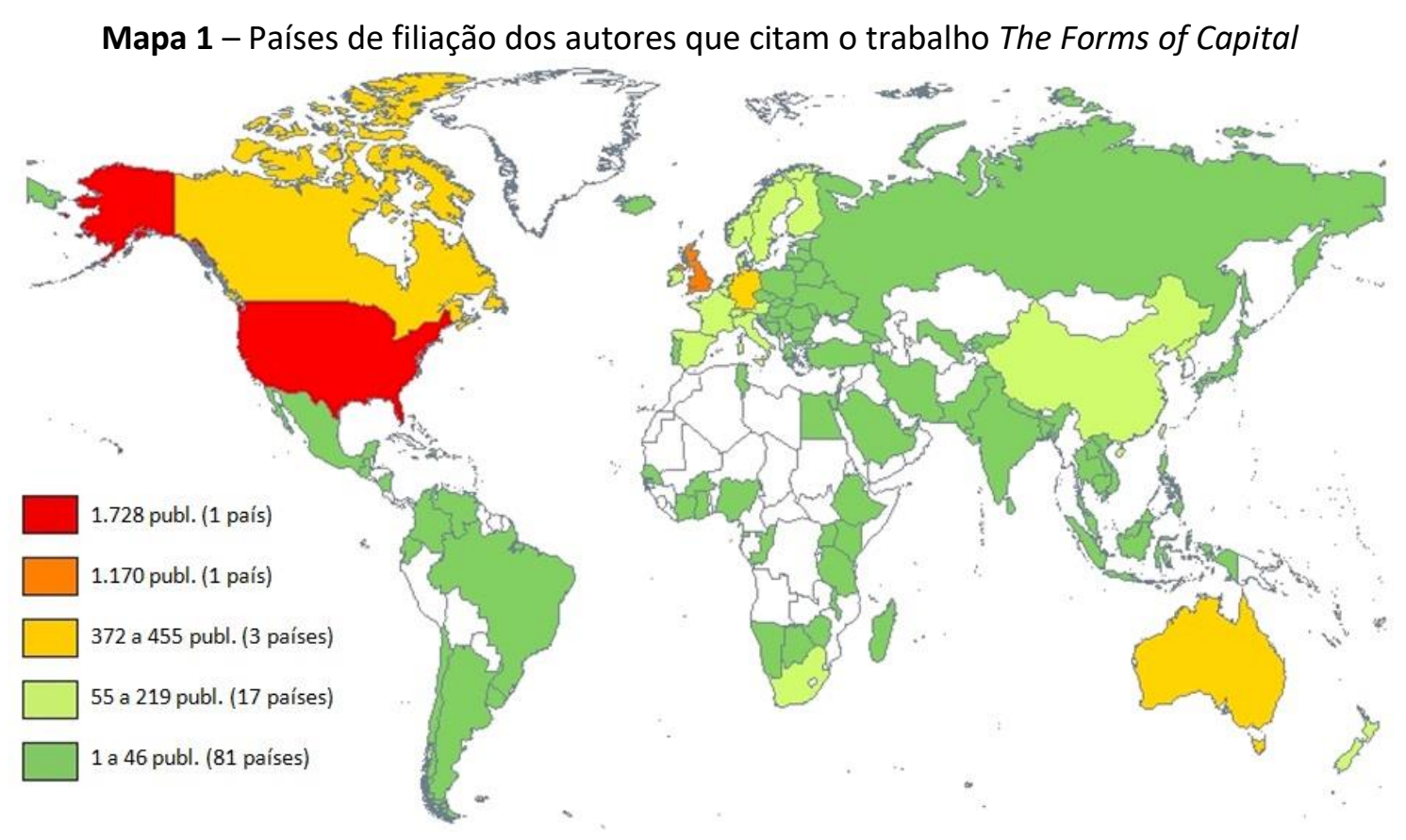

Fonte: Dados da pesquisa.

Os dados apresentados acima, de certa forma, corroboram a afirmação de que Pierre Bourdieu exerce influência não apenas sobre os pensadores franceses, mas sobre intelectuais de vários países e de outras disciplinas das ciências humanas e sociais, confirmando a sua notoriedade internacional (VALLE, 2007).

\section{Considerações finais}

O objetivo principal do estudo foi analisar o impacto do trabalho The Forms of Capital na literatura científica internacional indexada na base de dados Web of Science. Apesar das limitações da base para análise de uma obra das Ciências Sociais e Humanidades, considera-se que este estudo apresenta uma tentativa inicial para mapeamento das citações ao trabalho de Bourdieu. Indubitavelmente, novos estudos devem seguir um caminho mais abrangente, tentando realizar este mapeamento em bases de dados específicas destas áreas. Reconhecemos que o esforço para a construção de bases de dados e índices de citação de livros é fundamental para que se possa compreender plenamente a difusão e uso da informação científica nas Ciências Sociais e Humanidades.

Os resultados apresentados sugerem a internacionalização dos trabalhos que compõem o corpus do estudo, confirmada pelo idioma das publicações, pelos países que 
citaram o autor e pelo vínculo institucional dos autores. Grande parte dos artigos citantes foi publicada nas áreas da Sociologia, da Educação e Pesquisa Educacional e da Administração. Porém, o impacto de Bourdieu (1986) pode ser observado em áreas do conhecimento bem diversas, como as ciências da saúde, por exemplo. Os temas dos artigos que compõem o corpus parecem estar distribuídos em linhas de pesquisa bem definidas, como demonstrado na rede de coocorrência de palavras-chave dos autores e keywords plus. Além disso, os principais termos identificados no corpus estão coerentes com a proposta teórica e conceitual de Pierre Bourdieu. Por fim, percebe-se que as citações ao trabalho The Forms of Capital apresentam crescimento exponencial ao longo do tempo, o que indica que a relevância do trabalho do autor tem se mantido constante. $\mathrm{O}$ sociólogo de origem camponesa teve o mérito de construir uma obra tão consistente, robusta e relevante que ultrapassou as fronteiras geográficas e simbólicas do saber.

\section{Agradecimentos}

Agradecemos à Profa. Dra. Célia Elizabete Caregnato pelas sugestões a esse trabalho.

\section{Referências}

ARCHAMBAULT, Éric; LARIVIÈRE, Vincent. The limits of bibliometrics for the analysis of the social sciences and humanities literature. In: UNITED NATIONS EDUCATIONAL, SCIENTIFIC AND CULTURAL ORGANIZATION. World social science report: knowledge divides. Paris, 2010. p. 251-254. Disponível em: <http://ost.openum.ca/files/sites/132/2017/06/WSSR_ArchambaultLariviere.pdf>. Acesso em: $6 \mathrm{dez} .2017$.

BORTOLUCI, José Henrique; JACKSON, Luiz Carlos; PINHEIRO FILHO, Fernando Antonio. Contemporâneo clássico: a recepção de Pierre Bourdieu no Brasil. Lua Nova: revista de cultura e política, São Paulo, n. 94, p. 217-256, 2015.

BOURDIEU, Pierre. The forms of capital. In: Richardson, John G. (Ed.). Handbook of theory and research for the sociology of education. Westport: Greenwood Press, 1986. p. 241-258.

CATANI, Afrânio Mendes. A sociologia de Pierre Bourdieu (ou como um autor se torna indispensável ao nosso regime de leituras). Educação \& Sociedade, Campinas, v. 23, n. 78, p. 57-75, abr. 2002.

CATANI, Afrânio Mendes; CATANI, Denice Bárbara; PEREIRA, Gilson R. de M. As apropriações da obra de Pierre Bourdieu no campo educacional brasileiro, através de periódicos da área. Revista Brasileira de Educação, Rio de Janeiro, n. 17, p. 63-85, maio/ago. 2001.

ÉCOLE NORMALE SUPÉRIEURE. Sciences, humanities, social sciences. [2007?]. Disponível em: <http://www.ens.fr/IMG/file/a_propos_ens/ENS_brochure_us.pdf >. Acesso em: 6 dez. 2016. 
FERREIRA, Walace. Bourdieu e educação: concepção crítica para pensar as desigualdades socioeducacionais no Brasil. e-Mosaicos, Rio de Janeiro, v. 2, n. 3, p. 46-59, jun. 2013.

GARFIELD, Eugene. Is citation analysis a legitimate evaluation tool? Scientometrics, Amsterdam, v. 1, n. 4, p. 359-375, 1979.

MINAYO, Maria Cecília de Souza. Bourdieu e o ethos acadêmico. In: MARTELETO, Regina Maria; PIMENTA, Ricardo Medeiros (Org.). Pierre Bourdieu e a produção social da cultura, do conhecimento e da informação. Rio de Janeiro: Garamond, 2017. p. 7-13.

MONTAGNER, Miguel Ângelo. Pierre Bourdieu, o corpo e a saúde: algumas possibilidades teóricas. Ciência \& Saúde Coletiva, Rio de Janeiro, v. 11, n. 2, p. 515-526, abr./jun. 2006.

NOGUEIRA, Maria Alice. Capital cultural. In: CATANI, Afrânio Mendes et al. (Org.) Vocabulário Bourdieu. Belo Horizonte: Autêntica, 2017.

SIEWEKE, Jost. Pierre Bourdieu in management and organization studies: a citation context analysis and discussion of contributions. Scandinavian Journal of Management, v. 30, n. 4, p. 532-543, 2014.

SILVA, Márcia Regina da; HAYASHI, Maria Cristina Piumbato Innocentini. O que Bourdieu tem a dizer sobre a Bibliometria? In: SEGUNDO, José Eduardo Santarem; SILVA, Márcia Regina da; MOSTAFA, Solange Puntel (Org.). Os pensadores e a Ciência da Informação. Rio de Janeiro: Epapers, 2012. p. 9-24.

VALLE, lone Ribeiro. A obra do sociólogo Pierre Bourdieu: uma irradiação incontestável. Educação e Pesquisa, São Paulo, v. 33, n. 1, p. 117-134, jan./abr. 2007.

VALLE, lone Ribeiro. O lugar da educação (escolar) na sociologia de Pierre Bourdieu. Revista Diálogo Educacional, Curitiba, v. 13, n. 38, p. 411-437, jan./abr. 2013.

VANZ, Samile Andréa de Souza; CAREGNATO, Sônia Elisa. Estudos de citação: uma ferramenta para entender a comunicação científica. Em Questão, Porto Alegre, v. 9, n. 2, p. 295-307, jul./dez. 2003.

WACQUANT, Loïc J. D. O legado sociológico de Pierre Bourdieu: duas dimensões e uma nota pessoal. Revista de Sociologia e Política, Curitiba, n. 19, p. 95-110, nov. 2002. 